\title{
Direct agglutination test and other assays for measuring antibodies to Toxoplasma gondii
}

\author{
JULIE JOHNSON, KIM DUFFY, LINDA NEW, R E HOLLIMAN, B S CHESSUM, \\ D G FLECK The Public Health Laboratory Service, Toxoplasma Reference Laboratory, St George's \\ Hospital, London
}

SUMMARY The performance of a direct agglutination test for the detection of toxoplasma specific IgG immunoglobulin was compared with that of the latex agglutination test. The direct agglutination test was less sensitive but more specific than the latex agglutination test. Quantitative results were not directly comparable, reflecting the different antibody profiles detected in each assay.

The direct agglutination test represents an alternative to the latex agglutination test as a screening test for toxoplasmosis. Patients at risk of life threatening infection require detailed serological examination using additional assays.

The recognition of toxoplasmosis as a life threatening infection of the immunocompromised, and greater awareness of congenital toxoplasmosis, have emphasised the need for reliable methods of diagnosing this parasitic infection. The Sabin and Feldman dye test is still the serological test of choice, ${ }^{1}$ but this technically demanding bioassay is rarely performed outside reference centres.

The peripheral laboratory requires a reliable screening test for toxoplasmosis, while the reference laboratory may choose to run a second assay in parallel with the dye test to minimise erroneous results when large numbers of samples are processed. The latex agglutination test (Eiken Chemical Company, Tokyo) is widely used in this context. Previous studies have confirmed the suitability of this assay as a screening test ${ }^{2}$ but have documented a significant incidence of false positive results. ${ }^{3}$

In France, where the experience of toxoplasma infection is greater than that in the United Kingdom, a commercial direct agglutination test is in widespread use. The original direct agglutination test, described by Fulton and Turk, entailed the reaction of specific antibody with formalin-fixed, toxoplasma tachyzoites. ${ }^{4}$ The method lacked sensitivity, producing lower titres than those recorded by the dye test, and gave false positive reactions due to the binding of non-

Accepted for publication 12 Jamuary 1989 toxoplasma specific IgM immunoglobulin to the parasite. Subsequent modifications of the technique suppressed non-specific reactions by the use of 2 mercaptoethanol buffer and increased sensitivity by treatment of the tachyzoites with trypsin, producing a "sensitised" antigen. As the modified test is now available to laboratories in the United Kingdom we assessed the performance of this assay and compared it with the dye test and the latex agglutination test.

\section{Material and methods}

Four hundred stored sera, previously assayed with the dye test were selected for inclusion in the trial. One hundred samples, each with dye test results known to be of high $(\geqslant 1000)$, medium (512-128), low (64-16), or negative $(<16)$ titres were included and a further 591 serial samples sent to our unit from referring laboratories. Each serum sample included in the trial was assayed by the dye test, latex agglutination test, and direct agglutination test. For the initial 250 samples processed, any serum producing test results which differed by more than one doubling dilution were retested with all three assays. Twelve sera were selected to produce a range of dye test titres from $<16$ to 8000 . Each of these samples was assayed 10 times by all three tests to establish the reproducibility of results. Fifteen sera known to contain rheumatoid factor and 20 sera containing anti-nuclear factor were also processed. 
DYE TEST

The dye test was performed in flat bottomed microtitre plates and read directly using an inverted microscope, a modification of the test described by Sabin and Feldman' and Feldman and Lamb. ${ }^{6}$ The test was standardised against the Toxoplasma National Control Serum, which, in turn, has been standardised against the WHO International Control Serum issued by the State Serum Institute, Copenhagen, Denmark. The Toxoplasma National Control Serum, produced in our laboratory, comprises pooled serum samples derived from patients with toxoplasma lymphadenopathy and diluted to produce a consistent dye test result of $1000 \mathrm{IU} / \mathrm{ml}$. A positive control serum of known titre was also run with each batch of test sera. ${ }^{7}$

All sera with a dye test titre of $<16$ were defined as negative and those with titres of $\geqslant 16$ as positive throughout the analysis, regardless of results obtained by the latex agglutination or direct agglutination tests. A dye test titre of 16 equalled 4 IU.

\section{LATEX AGGLUTINATION TEST}

The Eiken toxoreagent test is an indirect latex agglutination test produced by the Eiken Chemical Company Ltd, Dunkyo-ku, Tokyo, Japan. A modified method was used, as previously described. ${ }^{2}$ The same antigen batch number was used throughout the course of the study. The test was performed in microtitre plates (u-shaped wells). Using an initial 1 in 2 dilution of the serum, doubling dilutions were prepared up to 1 in 4096. Latex antigen $(25 / \mu \mathrm{l})$ was then added to the 1 in 16 and the 1 in $64-1$ in 4096 wells. A positive latex agglutination test result was defined as that with a titre of $\geqslant 16$. The Toxoplasma National Control Serum and a positive control serum of known titre were run with each batch of test sera. Sera that proved positive up to and above a dilution of 1 in $\mathbf{4 0 9 6}$ were further diluted to 1 in 32768 .

\section{DIRECT AGGLUTINATION TEST}

The Toxo-Screen direct agglutination test kit is used for the detection of toxoplasma IgG antibodies by direct agglutination using a sensitised antigen and is produced by BioMérieux, France. IgM-mediated agglutination is suppressed by using a diluting buffer containing 2-mercaptoethanol. The assay was supplied as a kit containing $4 \mathrm{ml}$ of a suspension of Toxoplasma gondii treated with formalin and obtained from mouse ascitic fluid, $16 \mathrm{ml}$ of diluent (BABS colour buffer), $1 \mathrm{ml}$ of concentrated 2-mercaptoethanol which was diluted to give a $0.2 \mathrm{~mol} / \mathrm{l}$ solution, lyophilised positive and negative control sera (each to be diluted to $1 \mathrm{ml}$ ) and powdered phosphate buffered saline (PBS) to be diluted to one litre. Four microtitration plates, four self-adhesive plate covering sheets, and four report sheets were also included in the kit.
If the antigen is used as recommended-that is, diluted to 1 in 5 with diluent, $50 \mu \mathrm{l}$ per well, sufficient is provided for $\mathbf{4 0 0}$ wells. The kit has a shelf life of six months when stored at $2^{\circ} \mathrm{C}-8^{\circ} \mathrm{C}$. Two different antigen batches were used during the course of the study.

The test was performed in microtitre plates (ushaped wells). For screening the sera, two dilutions were prepared: a 1 in $20(100 \mu \mathrm{l}$ serum $+1.9 \mathrm{ml}$ PBS $)$ and a 1 in 2000 dilution ( $25 \mu$ l of the 1 in 20 dilution + $2.5 \mathrm{ml}$ of PBS). Each dilution ( $25 \mu \mathrm{l})$ was transferred into the microtitre trays and $25 \mu \mathrm{l}$ of $0.2 \mathrm{~mol} / 12$ mercaptoethanol added to each well, thus diluting the sera 1 in 40 and 1 in 4000 . The antigen $(50 \mu \mathrm{l})$ diluted 1 in 5 with the diluent was added to each well, the plate covered with a self-adhesive sheet, mixed thoroughly and left to stand at room temperature overnight. The Toxoplasma National Control Serum and a positive control of known titre were run with every batch of test sera. Agglutination patterns were determined using a mirrored plate reader.

A positive reaction exhibits agglutination of the toxoplasma in a mat covering about half of the well base. In the absence of specific antibody a compact button was obtained. A positive reaction in the screening test was confirmed by a quantitative test whereby $50 \mu \mathrm{l}$ of the 1 in 20 dilution was used to set up doubling dilutions from 1 in $20-1$ in 4096, and the same test procedure applied as previously described. The end point was taken as the highest serum dilution showing clinically important agglutination. A positive direct agglutination test result was defined as that with titre of $\geqslant 40$.

\section{Results}

False positive and false negative results obtained by latex agglutination test or direct agglutination test were defined as those discordant with the dye test findings, and clinical details concerning these patients were documented. A comparison of qualitative results obtained by the three assays is presented in table 1 . Assuming that dye test results are always accurate, the direct agglutination test produced fewer false positive but more false negative results than did the latex

Table 1 Qualitative comparison of toxoplasma latex agglutination test (LAT), direct agglutination test $(D A)$, and dye test $(D T)$ results

\begin{tabular}{lcr}
\hline & $D T+$ & $D T-$ \\
\hline LAT + DA + & 707 & 5 \\
LAT + DA - & 21 & 43 \\
LAT - DA + & 3 & 0 \\
LAT - DA - & 8 & 204 \\
\hline+ = positive - = negative & &
\end{tabular}


Table 2 Comparison of toxoplasma latex agglutination test and direct agglutination tests

\begin{tabular}{|c|c|c|}
\hline & $\begin{array}{l}\text { Latex } \\
\text { agglutination test }\end{array}$ & $\begin{array}{l}\text { Direct } \\
\text { agglutination test }\end{array}$ \\
\hline $\begin{array}{l}\text { Sensitivity } \\
\text { Specificity } \\
\text { Predictive values: }\end{array}$ & $\begin{array}{l}99 \% \\
81 \%\end{array}$ & $\begin{array}{l}96 \% \\
98 \%\end{array}$ \\
\hline $\begin{array}{l}\text { Positive result } \\
\text { Negative result }\end{array}$ & $\begin{array}{l}94 \% \\
95 \%\end{array}$ & $\begin{array}{l}99 \% \\
90 \%\end{array}$ \\
\hline
\end{tabular}

agglutination test. Sera producing false positive or false negative results came from many different types of patients. There did not seem to be any correlation with age, sex, presenting symptoms or immune competence. The sensitivity, specificity, and predictive values of latex agglutination test and direct agglutination test results were calculated by reference to dye test findings and are presented in table 2.

Analysis of the results of repeated testing of sera using the F-ratio test showed that the direct agglutination test was significantly less reproducible than either the latex agglutination test or the dye test $(p<0.05)$, but there was no significant difference in the reproducibility of latex agglutination test and dye test results. The presence of rheumatoid or antinuclear factor in sera produced no demonstrable effect on any of the three assays. Repeated testing of those sera among the initial 250 samples which produced discordant results by different assays confirmed the initial findings. Technical error was excluded as a cause of these discrepancies.

Titres obtained by the three assays were tabulated using result difference/mean plots to display relative
Table 3 Comparison of toxoplasma titres obtained from latex agglutination test (LAT), direct agglutination test $(D T)$, and dye test $(D T)$ assays

\begin{tabular}{lrrr}
\hline & $D T: L A T$ & $D T: D A$ & LAT:DA \\
\hline Mean difference & -0.47 & -2.96 & -2.49 \\
Standard deviation of the & 1.75 & 2.11 & 2.00 \\
differences & -3.97 & -7.18 & -6.50 \\
Limits of agreement & 3.02 & 1.26 & 1.53 \\
& & & \\
\hline
\end{tabular}

agreement. ${ }^{8}$ All titres were expressed as logarithms to base 2, reflecting the doubling dilution series used.

For the results from each pair of tests, the mean difference (d) and the standard deviation of the differences ( $s$ ) were calculated. The mean difference indicates the bias between the two tests and the standard deviation of the differences is indicative of their variability. Most points on the graphs are expected to lie between $d \pm 2 s$. These are the "limits of agreement."

Graphs showing the difference between the results of each assay plotted against the mean result are shown in figs $1-3$. The mean difference, standard deviation of the differences, and limits of agreement for each assay compared with those of the other two methods are shown in table 3 . The direct agglutination test gave results, on average, three doubling dilutions greater than the dye test and 2.5 doubling dilutions greater than the latex agglutination test. The latex agglutination test gave results, on average, 0.5 doubling dilutions greater than the dye test.

The standard deviation values indicate that the differences between the direct agglutination test and

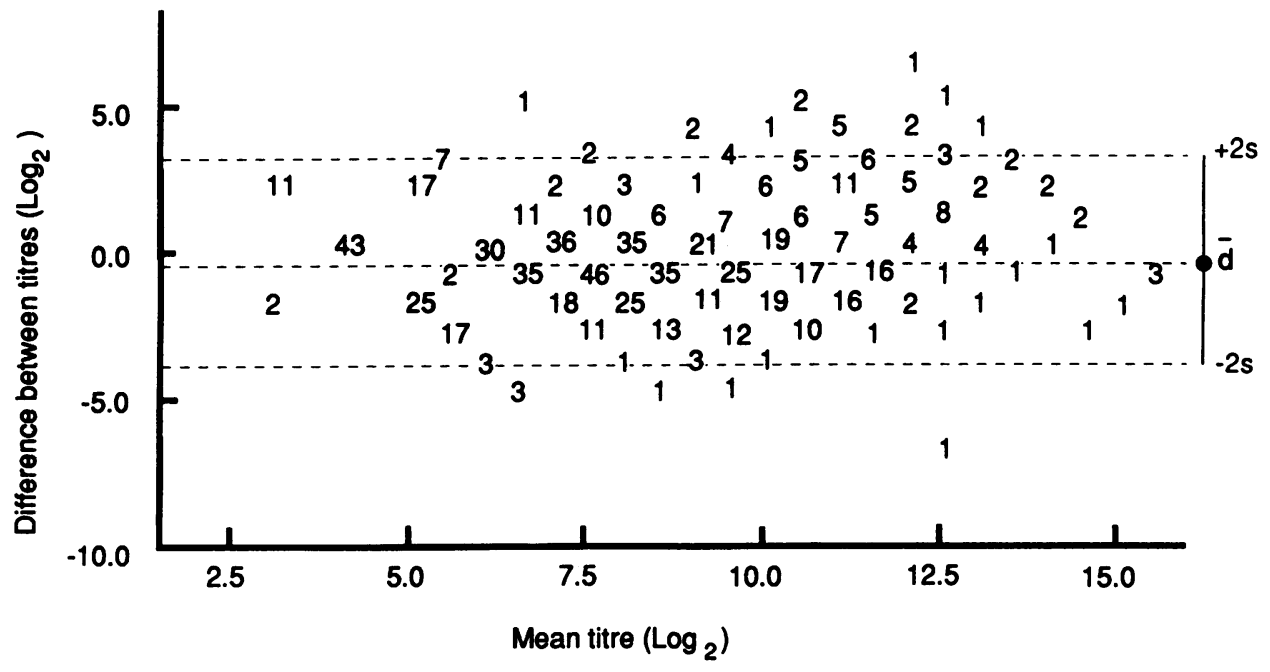

Fig 1 Graph showing correlation between dye test and latex agglutination test titres $\left(\log _{2}\right)$. 


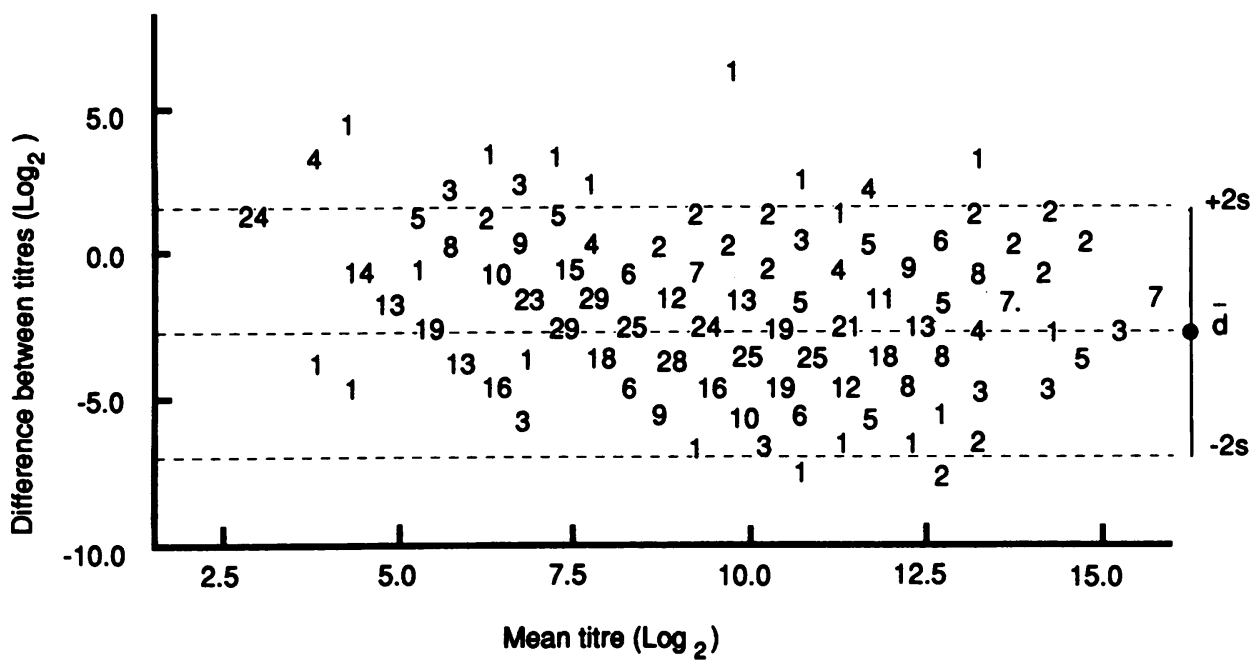

Fig 2 Graph showing correlation between dye test and direct agglutination test titres $\left(\log _{2}\right)$.

the dye test were more variable than those between the latex agglutination test and dye test. The results obtained by latex agglutination test agreed with the dye test more closely than did the direct agglutination test, both in terms of bias and variability of the differences. The direct agglutination test agreed more closely with the latex agglutination test than the dye test. Only $2-3.5 \%$ of the results lay outside the limits of agreement which is fewer than one would expect. This is likely to be because we were measuring discrete values of what was really a continuous variation.

\section{Discussion}

We assessed the performance of a direct agglutination test for the detection of antibodies to Toxoplasma gondii and compared the assay with a commonly used latex agglutination technique. Most toxoplasma infections are asymptomatic and the minority of patients with clinical evidence of infection have non-specific signs and symptoms such as lymphadenopathy and malaise. The dye test is highly specific and sensitive in the diagnosis of toxoplasmosis. ${ }^{9}$ Consequently, we

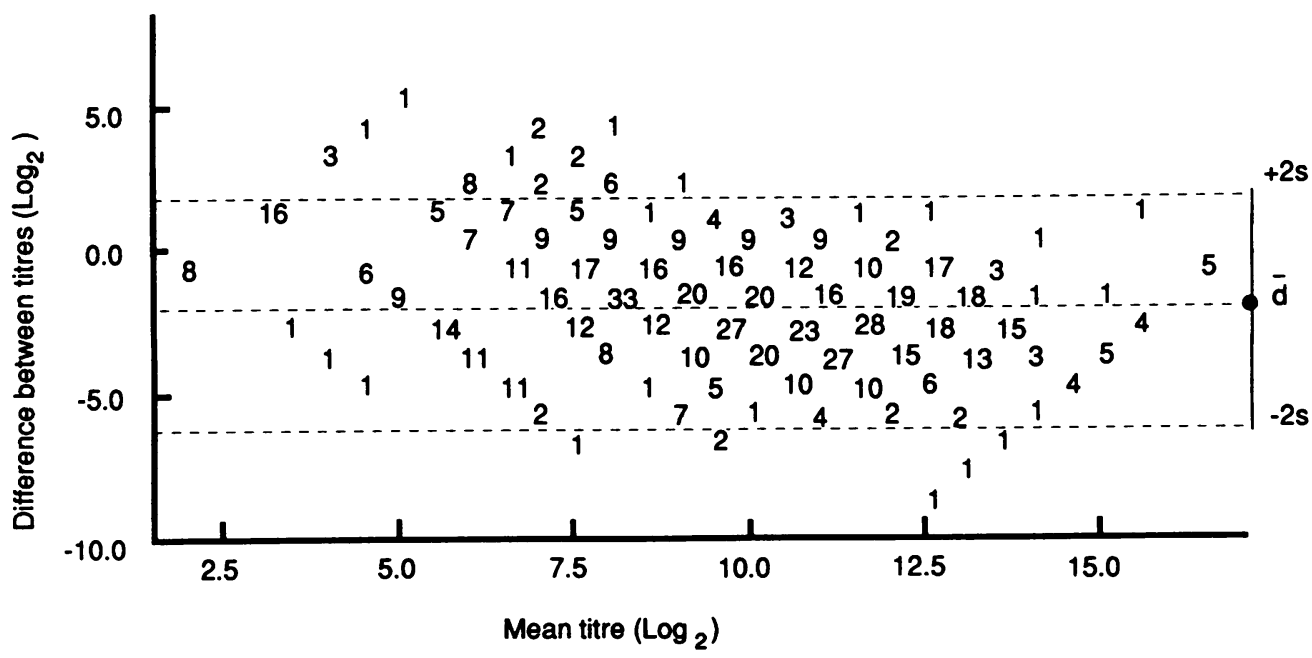

Fig 3 Graph showing correlation between latex agglutination and direct agglutination test titres $\left(\log _{2}\right)$. 
used this bioassay as the reference with which the other tests were compared. The incidence of false positive or false negative results recorded by the dye test is unknown. Sixty one dye test/latex agglutination test discrepant results, however, were documented in $\mathbf{4 4 5 0}$ samples tested. Further investigation of 18 of these discordant sera suggested that only one sample may have produced a misleading dye test result. ${ }^{3}$

In our hands, the direct agglutination test results were less reproducible than those derived from the dye test or latex agglutination test. These findings may represent an intrinsic property of the direct agglutination test. Alternatively, this difference may reflect our limited experience in performing and reading direct agglutination test reactions. The dye test and latex agglutination test have been used routinely in our laboratory for several years.

This study was not designed to assess ease of performance, but neither commercial assay was technically demanding and current costs were comparable. In its present form, however, the direct agglutination test includes the use of mercaptoethanol. It has been shown that the latex agglutination test is suitable as a screening assay for toxoplasma infection ${ }^{2}$ but not as a replacement for the dye test. ${ }^{10}$ Our findings confirm these conclusions and suggest a similar role for the direct agglutination test.

The conventional way of assessing agreement between two tests would be to plot the results of one against those of the other, and adding in the line of equality on which all points would lie if the two tests gave exactly the same results. Most of the points would be clustered around the line, however, and it would be difficult to assess any differences between the tests.

We compared titres obtained by three different tests by plotting the mean result against result differences of each pair expressed as logarithms (base 2). This method may be less familiar than that of comparing direct titres and calculating correlation coefficients, but it has the advantage of producing more information regarding the agreement of results and the nature of any differences. ${ }^{8}$ These figures show the discrepancy between titres obtained using each method and show that none of the assays is interchangeable. Differences in titres between assays reflect the different antigen profiles presented in each test for antibody detection and are related to the length of time the patient was infected. The direct agglutination test titre is most often greater than that of the dye test in cases of chronic infection but lower than the dye test titre when infection is acute. "Similarly, latex agglutination test titres rise later than those measured in the dye test in cases of acute toxoplasmosis but persist for a greater period of time. ${ }^{10}$ Insufficient clinical details were available to determine the stage of infection of the patients considered in the current study and we were unable to compare the variation of direct agglutination test and latex agglutination test titres during the course of infection. Further studies to resolve this question are in hand.

It has been shown that the direct agglutination test produces more false negative results than does the latex agglutination test. Other workers have confirmed the reduced sensitivity of the direct agglutination test when compared with the complement fixation test. ${ }^{12}$ Conversely, the latex agglutination test produced more false positive results than the direct agglutination test method. It has been established that most false positive latex agglutination test reactions are associated with IgM immunoglobulin, ${ }^{13}$ but the specificity of these antibodies remains uncertain.

The current study has shown that neither the presence of anti-nuclear factor nor rheumatoid factor in sera had a demonstrable effect on the performance of any of the three assays. We have previously shown that neither cytomegalovirus infection, inactivation of the sera, kit batch variation nor the presence of hepatitis B virus " $e$ " antigen in the sample are consistently associated with discordant latex agglutination test reactions. ${ }^{3}$

The direct agglutination test should be regarded as an alternative to the latex agglutination test for use in the diagnosis of toxoplasma infection. When considering which assay to utilise, the laboratory should define its own requirements of the test to be used. When optimal sensitivity is needed and reduced specificity can be accepted, then the latex agglutination test would be a rational choice. Alternatively, if specificity is the dominant concern then the use of the direct agglutination test would be appropriate. In many instances the small differences in sensitivity and specificity between the two tests would be of little clinical importance and the laboratory's choice would be based on additional factors such as cost, availability, and user preference. The investigation of immunocompromised patients at risk of life threatening toxoplasmosis (fetus, those with malignancy, or human immunodeficiency virus infection, and transplant recipients) requires detailed examination with additional tests. Samples taken from these patients should be considered for referral to a reference centre, irrespective of the findings in the primary laboratory.

Toxo-screen direct agglutination test kits were provided by API-BioMérieux (UK) Limited, Basingstoke, Hampshire.

We are grateful to Mrs I Crossman for her secretarial assistance and Dr J M Bland for his expert statistical advice. 


\section{References}

1 Sabin AB, Feldman HA. Dyes as microchemical indicators of a new immunity phenomenon affecting a protozoan parasite. Science 1948;108:660-3.

2 Balfour AH, Fleck DG, Hughes HPA, Sharp D. Comparative study of three tests (dye test, indirect haemagglutination test, latex agglutination test) for the detection of antibodies to Toxoplasma gondii in human sera. J Clin Pathol 1982;35: 228-32.

3 Holliman RE, Johnson J, Duffy K, New L. Discrepant toxoplasma latex agglutination test results. J Clin Pathol 1989;42:200-3.

4 Fulton JD, Turk JL. Direct agglutination test for Toxoplasma gondii. Lancet 1959;ii:1068-9.

5 Desmonts G, Remington JS. Direct agglutination test for diagnosis of toxoplasma infection: Method for increasing sensitivity and specificity. J Clin Microbiol 1980;ii:562-8.

6 Feldman HA, Lamb GA. A micromodification of the dye test. $J$ Parasitol 1966;52:415.

7 Fleck DG, Kwantes W. The laboratory diagnosis of toxoplasmosis. Public Health Laboratory Service Monograph 13. London: HMSO, 1980.

8 Bland JM, Altman DG. Statistical methods for assessing agreement between two methods of clinical measurement.
Lancet 1986;i:307-10.

9 Sousa OE, Saenz RE, Frenkel JK. Toxoplasmosis in Panama: a 10 year study. Am J Trop Med Hyg 1988;38:315-22.

10 Payne RA, Francis JM, Kwantes W. Comparison of a latex agglutination test with other serological tests for the measurement of antibodies to Toxoplasma gondii. J Clin Pathol 1984;37:1293-7.

11 Desmonts G. Dépistage de la toxoplasmose par agglutination des parasites. Intérêt d'un antigène très sensible pour la recherche des immunoglobulines G spécifiques. Ann Biol Clin 1983;41: 139-43.

12 Mastracchio G, Martinetto P, Savoia D. Toxoplasmosi: diagnosi sierologiche comparate (AD, FC, IHA) per tentare di chiarire i diversi periodi dell'infezione nell'uomo. G Bacteriol Virol Immunol 1983;76:62-103.

13 Oshima T, Ando K, Suzuki $H$, et al. False positive reactions due to non-specific IgM in the toxoplasma indirect latex agglutination test. Igaku-No-Ayumi 1982;121:485-7.

Requests for reprints to: Julie Johnson, Public Health Laboratory, St George's Hospital, Blackshaw Road, London SW17 0QT, England. 